\title{
The 2015 International Psychogeriatric Association Junior Research Awards in Psychogeriatrics
}

Early in 2015, I was asked to chair the judging panel for the 2015 International Psychogeriatric Association (IPA) Junior Research Awards in Psychogeriatrics, and was pleased to help in this way for the second Congress in succession. The other five judges who kindly gave up their time to assist with the selection of the three prize winners were Nicola Lautenschlager, an old age psychiatrist from Australia, co-opted to the panel in her role as the current Editor-in Chief of International Psychogeriatrics (the three winning papers are published in this issue as has been traditional for over 25 years), Glenna Dowling, a nurse from the USA who is also an associate editor of International Psychogeriatrics, Karen Ritchie, a psychologist working in France, Martina Roes, a nurse turned sociologist from Germany, the host country for the 2015 IPA Congress, and Huali Wang, a psychiatrist from Beijing, China. Depending on how you look at it, our panel consisted of three psychiatrists, one psychologist, two nurses and a bonus sociologist, five judges from developed countries and one from a developing nation, or five women and one man, which I think is the first time that such an IPA prize judging panel has had a female majority.

The prizes were open to researchers within five years of the award of their terminal degree (e.g. MD, $\mathrm{PhD}$ ) who were not above instructor or assistant professor level at the time of submission and had not won one of these awards before. All entrants were required to report previously unpublished original research. In addition to publication of their papers in International Psychogeriatrics, each winner received complimentary congress registration for the October 2015 IPA Congress in Berlin, $\$$ US 1500 to assist with expenses and a complimentary one year IPA membership package.

The papers submitted for the prize were 24 in number (an increase of 13 over last time) and originated from young investigators in 13 different countries. In an initial judging process, during which judges from the same countries as authors of papers submitted for judging were excluded from the assessment of those papers, we whittled them down to the 9 we considered to be the best (there was a clear separation in rated quality between the
9 chosen for the final judging and the other 15), then all judges assessed each remaining paper on a six-point scale, and each paper's scores from each judge were added together. The first prize winner's final score stood out from the rest of the field, but we required a countback to split the second and third prize winners, both of whom achieved the same numerical result. One was preferred by three judges to two with the sixth judge being unable to split them.

Our first prize winner is Mark Oldham, an assistant professor of psychiatry at the Yale School of Medicine in New Haven CT, USA. Delirium is a common and serious complication for individuals undergoing coronary artery bypass surgery, and this initial report by Oldham and colleagues on a prospective study of cognitive and functional predictors of post-operative delirium reveals that certain forms of Mild Cognitive Impairment (MCI) predict subsequent delirium. Thus, the study has the potential to inform practice - if we know who is likely to become delirious we can focus interventions for delirium prevention upon such patients undergoing this widely performed operation, with possible benefit to their health and well-being.

The second prize was won by Timo Grimmer, a doctor from the psychiatry and psychotherapy department at the Technical University of Munich in Bavaria, Germany. Using a huge database of attendees at a memory clinic which has been operating since 1985, he and his co-authors were able to show that as public knowledge about late life cognitive decline and the availability of treatments has improved over time, patients are being referred and diagnosed at earlier and earlier stages of decline over a quarter of a century.

The third prize winner was Donnamay Brown from the pharmacy department at the School of Medicine in Hobart, capital city of Australia's island state of Tasmania. She and her co-researchers, who include Juanita Westbury, a former IPA junior research prize winner from 2009, assessed residents from four nursing homes, to show the importance of sleep problems and benzodiazepine use in the etiology of agitation, a frequent cause of distress for nursing home residents and their carers around the globe. 
On behalf of my co-judges and IPA, I extend my congratulations to the three prize winning authors and look forward to seeing the impact of their research findings and to watching their careers develop over the next few years. I would like to thank all those who submitted papers for judging (as Lewis Carroll was not in charge, we could not give prizes to everyone, but there were many worthy entrants, some of whom we hope will submit their excellent papers for possible publication as regular contributions to International Psychogeriatrics), the judges for taking the time and trouble to assess the submitted papers, as well as Debra Gallagher and Susan Oster from IPA for their enthusiastic and effective management of the entire submission and judging process.

\section{DAVID AMES}

National Ageing Research Institute and University of Melbourne Academic Unit for Psychiatry of Old Age, Melbourne, Australia

Email: dames@unimelb.edu.au 